\title{
Enfuvirtida para o tratamento do paciente com aids: o divisor de águas
}

\author{
Enfuvirtide in the treatment of AIDS patient: the turning point
}

Daniele Viana M aia Torres ${ }^{1}$

Karla Corrêa Lima M iranda ${ }^{2}$

${ }^{1}$ Centro de Ciências da Saúde, Universidade Estadual do Ceará. Av. Paranjana 1700, Itaperi. 60740-000 Fortaleza CE. danivmaia@ig.com.br

${ }^{2}$ Departamento de Enfermagem, Centro de Ciências da Saúde, Universidade Estadual do Ceará.
Abstract Thestudy was carried out in a H ospital of Reference in Infectious Diseases of Ceará, from February 2006 to February 2007, and and aimed at identifyingthesocio-demographic profile of Enfuvirtide users and their main difficulties/facilities in previous and current treatment scheme. The initial sample analyzed the medical record of $23 \mathrm{pa}-$ tients; 18 agreed to participate, comprising the final sample. Thedescriptiveanalysis of quantitativedata wascarried out through thedistribution of frequencies and quantitative data, submitted for content analysis. It was observed that $83 \%$ weremale, $78 \%$ were single and the majority was between 30 and 52 years old and, in average, eight years and a half of antiretroviral treatment. From qualitative data, two categories emerged: (1) Previous treatment: difficulties and adversities and (2) Current treatment: from cognition to ability. The difficulties to conduct previous treatments were related to the size and high amount of tablets and side effects. As for facility, the easy drug administration was indicated. Regarding the current treatment, the difficulties were self administration and nodules on the sites whereEnfuvirtidewasapplied and thefacilities were absence of gastrointestinal effects and improvement of viral load. It's important to implement an interdisciplinary work that helps patients overcome the difficulties of the treatment, in addition to works in groups in order to better address the difficulties and help increase adhesion to treatment. Key words Aids, Treatment, Enfuvirtide
Resumo 0 estudo, realizado em um Hospital de Referência em Doenças Infecciosas do Ceará, de feverei ro de 2006 a fevereiro de 2007, visou identificar o perfil sociodemográfico dos usuários de Enfuvirtida e as principais dificuldades e facilidades encontradas por el es durante o tratamento anterior e 0 atual. A amostra inicial teve 23 pacientes; destes, 18 concordaram em participar. A análise descritiva dos dadosquantitativosfoi realizada pela distribuição de frequências e os dados qualitativos, submetidos à análise de conteúdo. O bservouse que $83 \%$ eram do sexo masculino, $78 \%$ eram solteiros ea maioria tinha entre 30 e 52 anos e em média oito anos e meio de tratamento antirretroviral. Dos dados qualitativos, emergiram as categorias (1) Tratamento anterior: dificuldades e adversidades e (2) Tratamento atual: da cognição à habilidade. As dificuldades dos tratamentos anteriores eram o tamanho ea quantidade el evada de comprimidos e aos efeitos colaterais; a facilidade apontada foi o fácil manejo da medi cação. Quanto ao tratamento atual, as dificuldadesforam a autoadministração e os nódulos nos locais de aplicação da Enfuvirtida eas facilidades, a ausência de efeitos gastrointestinais e melhora da carga viral. É importante implementar um trabalho interdisciplinar queajude os pacientes a vencer as dificuldades no tratamento, além de trabalhos em grupos para melhor abordar as dificuldades e ajudar a aumentar a adesão à terapêutica.

Palavras-chave Aids, Tratamento, Enfuvirtida 
Introdução

A Síndrome da Imunodeficiência Adquirida (aids), doença causada pelo vírus da imunodeficiência humana (HIV), vem se tornando cada vez mais frequente na população mundial, sendo, portanto, considerada um sério problema de saúde da atualidade.

Segundo dados do último Boletim Epidemiológico, até junho de 2006, foram notificados ao todo no Brasil 433.067 casos de aids ${ }^{1}$.

Diante desta grande dimensão alcançada pela aids, diversos foram os estudos realizados com 0 intuito de entender a fisiopatologia desta doença e procurar meios para combatêla, visando melhorar a qualidade de vida e minimizar o sofrimento de seus portadores.

Em 1996, na 11a Conferência Internacional sobre a Aids, em Vancouver, Canadá, foi apresentada uma associação de medicamentos, denominada coquetel dedrogas, que diminuiria em cem vezes o ritmo de reprodução do vírus em relação à monoterapia até então empregada. Esta combinação de medicamentos utilizaria drogas capazes de inibir diferentes etapas da replicação viral, sendo classificadas de acordo com as enzimas virais queinibem, dividindo-se em três categorias: inibidores da transcriptase reversa análogos de nucleosídeos (ITRN), inibidores da transcriptase reversa não-análogos de nucleosídeos (ITRN N) e inibidores de protease (IP)².

Porém, apesar de todos estes avanços alcançados pela terapia antirretroviral combinada, uma das grandes dificuldades vivenciadas pelos pacientes é seguir o tratamento corretamente. Aumentar a aderência dos pacientes ao tratamento antirretroviral constitui uma questão de primeira ordem no combate à evolução da epidemia ${ }^{3}$.

Desta forma, procura-se evitar o desenvolvimento de droga-resistência decorrente de mutações virais que fazem com queos antirretrovirais utilizados no tratamento de um determinado paciente passem a não responder mais de forma satisfatória.

$\mathrm{N}$ a tentativa de reverter esta situação de fal ha terapêutica, foram desenvolvidas drogas, denominadas inibidores de fusão, como é o caso da Enfuvirtida. "As drogas desta classe interferem com a entrada do HIV em células linfocitárias por inibirem a fusão das membranas viral e celular" 4 .

A Enfuvirtida foi a primeira droga desta classe aprovada para uso clínico em 2003, como parte da terapia de resgate. Deve ser administrada por via subcutânea em duas aplicações diárias ${ }^{4}$. Portanto, ela traz consigo uma certa exigência de destreza, desenvolvimento cognitivo e aceitação por parte dos pacientes que a utilizam. Estes aspectos motivaram a realização deste estudo, que teve como objetivos identificar o perfil sociodemográfico dos pacientes que utilizam a Enfuvirtida e as principais dificuldades encontradas pelos pacientes durante o tratamento com os esquemas anteriores e 0 atual.

Acredita-seque os resultados do presentetrabalho servirão de subsídios aos profissionais de saúde que acompanham estes pacientes, no sentido de poder conhecer como o tratamento proposto está sendo conduzido por estes, identificando os pontos que devem ser trabalhados e melhorados.

\section{M etodologia}

0 presenteestudo édescritivo eexploratório com abordagem qualitativa. Foi realizado entre fevereiro de 2006 efevereiro de 2007 em um H ospital de Referência em Doenças I nfecciosas do Estado do Ceará, no município de Fortaleza.

Os sujeitos do estudo foram 23 pacientes atendidos no SAE, com diagnóstico de aids, considerados em fal ha terapêutica e que estavam fazendo uso da Enfuvirtida há pelo menos um mês. Todos tiveram seus prontuários consultados e dezoito destes participaram das entrevistas, após terem sido contatados e concordarem em participar da pesquisa.

0 estudo desenvolveu-se em dois momentos. Inicialmente, realizou-se um levantamento de dados em prontuários através da utilização de um questionário com perguntas abertas efechadas, contendo informações sobre variáveis demográficas e sociais, além de dados sobre 0 esquema terapêutico. Posteriormente, mantevese contato com estes pacientes e, através de solicitação verbal, foram convidados a participar do estudo e com os que concordaram. Realizou-se entrevista semiestruturada, explorando aspectos inerentes aos tratamentos anteriores e 0 atual e, além disso, foi solicitada autorização aos entrevistados para a gravação das falas para posterior transcrição e melhor análise dos dados.

A análise descritiva dos dados quantitativos foi realizada através da distribuição de frequências e al guns destes foram organizados em tabelas para melhor visualização e análise.

Realizou-se a técnica da análise de conteúdo fundamentada em Bardin ${ }^{5}$ para análise dos dados qualitativos. Para tanto, foram transcritos os dados obtidos através das entrevistas para 
facilitar a análise. Posteriormente, foi realizada uma leitura superficial destas, seguida de leituras exaustivas do material empírico. 0 corpus foi definido em dezoito entrevistas, que corresponderam à totalidade dos sujeitos do estudo. Trabalhou-se os dezoito corpus inventariando este material e dividindo as falas em unidades de registro por meio de frases, sempre as relacionando com o objetivo do estudo. Desta forma, foram obtidas 679 unidades de registro, que foram condensadas em 23 subcategorias e estas, por sua vez, organizadas em quatro categorias. N estetrabalho, somente duas serão abordadas: (1) Tratamento anterior: dificuldades eadversidades; (2) Tratamento atual: da cognição à habilidade.

\section{Resultadosediscussão}

\section{Caracterização dos sujeitos}

Dos 23 sujeitos da pesquisa que tiveram seus prontuários analisados, dezenove (83\%) eram do sexo masculino equatro (17\%), do sexo feminino. Quanto à faixa etária, seis estavam na faixa etária de 30 a 36 anos, oito, na faixa etária de 37 a 42 anos, quatro, na faixa de 43 a 47 anos ecinco, na faixa de 48 a 52 anos de idade.

Com relação ao estado civil, dezoito (78\%) pacientes eram soltei ros e cinco (22\%), casados. Carvalho et $a^{3}{ }^{3}$. também identificaram em seu estudo uma proporção maior de solteiros, $62 \%$. Esta maior proporção de solteiros pode justificar em parte os $67 \%$ dos pacientes que fazem a autoadministração (Tabela 1), já que para estes talvez seja mais difícil encontrar alguém para compartilhar a condução da terapêutica. Já para os casados, o companheiro aparece como um cuidador que divide a responsabilidade das aplicações da medicação, administrando-a em locais do corpo no qual o próprio paciente não consegue aplicar ou mesmo assumindo esta ta-

Tabela 1. Distribuição dos pacientes em uso da Enfuvirtida segundo administração da medicação. H ospital São José de Doenças I nfecciosas. Fortaleza (CE), 2007.

\begin{tabular}{lrr}
\hline Tipo de administração & \multicolumn{1}{c}{$\mathrm{N}$} & \multicolumn{1}{c}{$\mathrm{f} \%$} \\
\hline Autoadministração & 12 & 67 \\
Administração por terceiros & 6 & 33 \\
Total & 18 & 100 \\
\hline
\end{tabular}

refa quando o paciente não se acha capaz de realizar a autoadministração.

Com relação à escolaridade, o grupo apresentou-seda seguinteforma: cinco pacientes não haviam concluído o ensino fundamental (22\%), três concluíram o ensino fundamental (13\%), quantro não concluíram o ensino médio (17\%), seis haviam concluído o ensino médio (26\%) e cinco concluíram o ensino superior (22\%).

Observou-se que este último fator interferiu na correta condução do tratamento com a Enfuvirtida, visto que os pacientes que apresentavam um maior nível de escolaridade mostravam um melhor entendimento do tratamento proposto e conseguiam conduzi-lo sem maiores dificuldades.

No grupo analisado, oito pacientes (35\%) tinham ocupação e quinze (65\%) não trabalhavam. Este fator está relacionado com a condução do tratamento, conforme será mostrado mais adiante, pois os que trabalham têm a dificuldade de encaixar o horário para tomar a medicação e ainda não podem fazê-lo no ambiente de trabalho por não quererem que os colegas tomem conhecimento do seu estado sorológico. Enquanto os que não trabalham têm mais tempo disponível para dedicar-se ao tratamento e podem fazêlo de forma mais cômoda. Além disso, identificou-se uma elevada percentagem de pacientes em idade produtiva e que não se encontram trabalhando.

Também foi verificado o ano deinício do tratamento antirretroviral pelos sujeitos da pesquisa. As datas variaram de 1994 a 2003 (Figura 1), distribuídas da seguinte forma: um pacienteiniciou tratamento em 1994, um paciente iniciou em 1995, cinco pacientes iniciaram em 1996, seis pacientes, em 1997, três, em 1998, três, em 1999, dois, no ano de 2002 e dois, em 2003. Estes tinham em média oito anos de tratamento e encontravam-se fazendo uso de um esquema de resgate, em que está contemplada a Enfuvirtida. Isto levou a questionar sobre os fatores que contribuíram para que os pacientes falhassem tão precocemente com os esquemas anteriores, principalmente considerando aqueles que iniciaram o tratamento em 2003, ou seja, apenas com três anos de tratamento com antirretrovirais orais.

Observou-se que o número de trocas de esquemas é grande entre os sujeitos analisados, variando desde uma até dezessete trocas (Tabela 2): seis pacientes já fizeram de uma a três trocas, dez já trocaram de quatro a seis vezes, três trocaram de sete a nove vezes, dois pacientes já trocaram de dez a doze vezes, um fez treze trocas e um fez dezessete trocas. Isso vem a dificultar a con- 
dução do tratamento, pois a cada nova troca de esquema, há uma nova exigência de adaptação e adequação do mesmo na rotina destes pacientes.

Quanto à interrupção do tratamento anterior, observou-se que sete pacientes $(30 \%)$ referiram nunca ter interrompido e dezesseis (70\%) informaram ter interrompido o tratamento em algum momento.

Já com relação ao tratamento atual, a interrupção da terapêutica foi referida por dois (12\%) dos entrevistados e negada por dezesseis ( $88 \%$ ), sendo que o motivo principal desta interrupção também estava relacionado às reações da medicação; no caso da Enfuvirtida, os nódulos nos locais da aplicação.
$N$ a tentativa de mensurar as dificuldades encontradas pelos pacientes para conduzir 0 atual tratamento, perguntou-se aos mesmos, qual seria o grau de dificuldade de 0 a 10, obedecendose às seguintes referências: 0 (sem dificuldade); 1 a 2 (muito baixa); 3 a 4 (baixa); 5-6 (regular); 7 8 (alta) e 9-10 (muito alta). Os resultados obtidos constam da Tabela 3 e mostram que dois pacientes consideravam o tratamento sem dificuldade, dois consideravam uma dificuldade muito baixa, seis relataram uma dificuldade regular, cinco referiram dificuldade alta etrês citaram uma dificuldade muito alta em conduzir o tratamento atual.

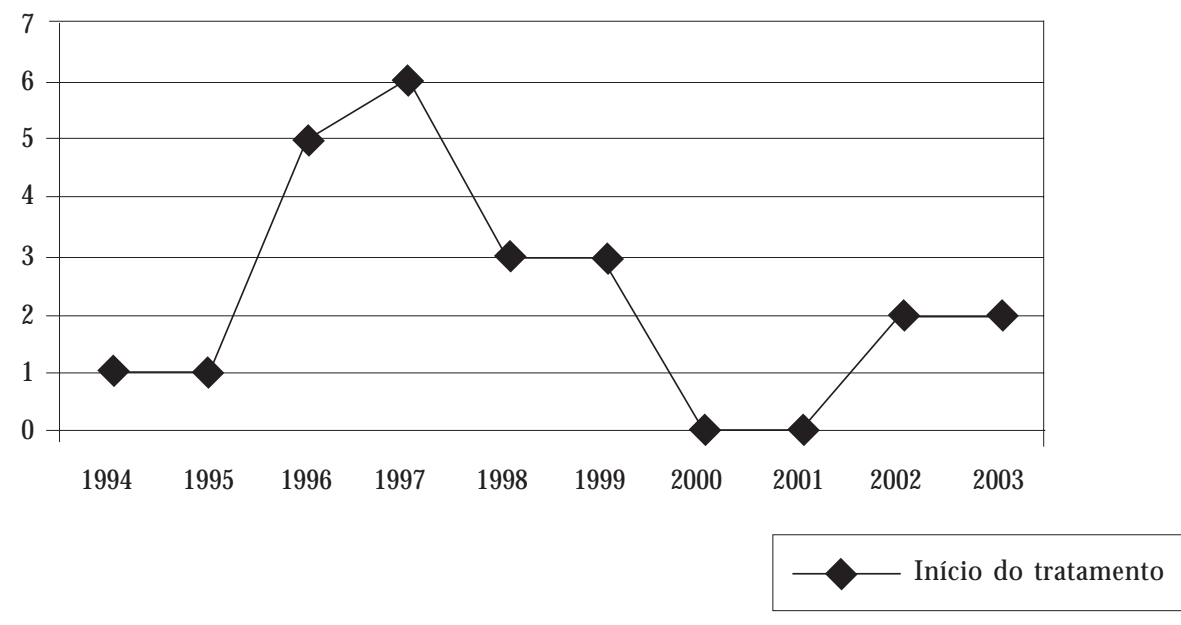

Figura 1. Distribuição dos pacientes em uso da Enfuvirtida segundo início do tratamento anti-retroviral. H ospital São José de Doenças Infecciosas. Fortaleza (CE), 2007.

Tabela 2. Distribuição dos pacientes em uso da Enfuvirtida segundo trocas de esquemas terapêuticos. Hospital São José de Doenças Infecciosas. Fortaleza (CE), 2007.

\begin{tabular}{lrr}
\hline No de trocas & Pacientes & $f \%$ \\
\hline $01-03$ & & \\
$04-06$ & 10 & 26 \\
$07-09$ & 3 & 13 \\
$10-12$ & 2 & 9 \\
$13-15$ & 1 & 4 \\
$16-17$ & 1 & 4 \\
Total & 23 & 100
\end{tabular}

Tabela 3. Distribuição dos pacientes em uso da Enfuvirtida segundo grau de dificuldade do tratamento atual. Hospital São José de Doenças Infecciosas. Fortaleza (CE), 2007.

\begin{tabular}{lrr}
\hline \multicolumn{1}{c}{ Pacientes } & N & $f \%$ \\
Grau de dificuldade & & \\
\hline 0 & 2 & 11 \\
$1-2$ & 2 & 11 \\
$3-4$ & - & - \\
$5-6$ & 6 & 33 \\
$7-8$ & 5 & 28 \\
$9-10$ & 3 & 17 \\
Total & 23 & 100 \\
\end{tabular}


Identificou-se na Tabela 3 que dos dezoito pacientes estudados, catorze tinham algum grau de dificuldade no manejo da medicação, o que faz necessária atenção e acompanhamento sistemático pela equipe interdisciplinar, em particular pelo enfermeiro, pois é necessário, além de dispensar a medicação, acompanhar individualmente o paciente, seu grau de dificuldadee orientações em relação a cada paciente.

Análise das falas dos sujeitos

No processo de análise do material empírico, foram identificadas quatro categorias e duas serão exploradas. A primeira contempla as questões relacionadas ao tratamento anterior e a segunda refere-se ao tratamento atual.

Categoria 1 - Tratamento anterior:

dificuldades e adversidades

Esta categoria tratou da visão dos pacientes acerca dos tratamentos anteriores, ou seja, abordou fatores percebidos por estes como facilitadores e/ ou dificultadores da continuidade do tratamento, as trocas de esquemas, as interrupções de tratamento e a percepção destes quanto à faIha terapêutica.

0 tratamento antirretroviral contempla drogas que irão atuar em diferentes etapas da replicação do vírus da imunodeficiência humana (HIV $)^{6}$. Com isto, os esquemas propostos normalmente compreendem uma grande quantidade de comprimidos, o que acaba, muitas vezes, por dificultar a adesão ao tratamento: Assim, eu sempre consegui meadaptar muito bem aos esquemas quemeeram propostos, mas eu tive problemas porque teve uma época em que eu tomava muitos comprimidos. 0 que eu achava mais ruim eram os comprimidos. (Entrevistado 1)

Este fato está de acordo com Leite, Silvana $N$ air et al. ${ }^{7}$, que referem que a dificuldade pode também estar relacionada à quantidade de medicamentos prescritos.

0 tamanho dos comprimidos também foi apontado como um dificultador, principalmente nos esquemas que contemplavam o Kaletra, de acordo com as seguintes falas: Antes eu tinha dificuldade no Kaletra. Eu acho que o que era muito incômodo do Kaletra era por causa do tamanho. (Entrevistado 16)

Conforme $\mathrm{N}$ emes et al. ${ }^{8}$, as razões para o paciente ter dificuldade à adesão estão associadas à grande quantidade de comprimidos ingerida diariamente, tamanho do comprimido erestrição dietética.
A dificuldade de encaixar os horários dos medicamentos na rotina e a falta de diálogo com 0 médico para adequar estes horários também foram apontados como fatores de não adesão ou mesmo de interrupção do tratamento, explicitado pelo seguinte depoimento: Eu passei um ano sem tomar medicação. U m ano não, foi num ano eu arrumei um emprego, fui trabalhar de manhã e os horários batiam com o emprego. Aí eu só tomava a medicação da noite, quer dizer só tomava uma parte da medicação. Eu não tive a maturidade de procurar um outro horário. Eu achava que tinha que ser aquele horário que a médica tinha estipulado. Aí, só depoisqueela dissequeeu poderia ter mudado o horário das medicações. (Entrevistada 1)

Tunala et al. ${ }^{9}$ confirmam esta idéia relatando que os horários prescritos sem levar em conta a vida e o cotidiano do paciente se tornam inoportunos, dificultando a adesão.

Freire ${ }^{10}$ teoriza sobreo papel do diálogo entre educador e educando. Vale salientar que o profissional de saúde se configura em educador quando trabalha adesão, sendo impossível dicotomizar o papel do clínico e do educador. Desta forma, para um trabalho consciente e eficaz em adesão, ambos têm de se fundir.

Ao interromper o tratamento, pode-se levar à resistência viral e, com isso, à necessidade de fazer ajustes nos esquemas terapêuticos, provocando frequentes trocas, atribuídas pel os pacientes à fal ha terapêutica: Eu não me dei bem com alguns medicamentos. Eu ficava acompanhando quase mensalmente as minhas taxas, quando tava bem, tudo bem. Quando começava a baixar, eu tinha que trocar o medicamento. (Entrevistado 5)

Eu tomava os medicamentos normal. Eu sempre tomei. Com um certo tempo, eles perdiam o efeito. (Entrevistado 7)

Os motivos destas interrupções relatadas pela mai oria dos pacientes estavam relacionados aos efeitos colaterais aos medicamentos orais, principalmente os distúrbios gastrointestinais, conforme identificou-se nas falas a seguir: Antes eu tinha muita reação, vomitava, ficava empachada, me dava mal-estar. (Entrevistada 18)

0 último que eu tomei foi aquele que não me dei bem, me deu muita diarréia e por causa dessa diarréia minha imunidade foi lá pra baixo. (Entrevistado 5)

Coadunando com este fato, Acurcio e Guimarães ${ }^{11}$ referem que as intensas reações adversas e efeitos colaterais aos medicamentos são 0 suficiente para provocar a interrupção do uso, seja por decisão própria ou por recomendação médica. 
Entretanto, éimportante estar atento ao diálogo entre paciente e profissional. É importante pensar no paciente como uma pessoa ativa no seu processo de tratamento, capaz de se posicionar e fazer escolhas, não meramente como expectador da decisão do profissional. Precisa-se aprender eter capacidade de escutar a necessidade, o contexto de vida do outro, questão que muitas vezes é penosa para o profissional que é treinado para a prescrição, normatização e imposição de suas idéias ao outro.

Quando questionados sobre o motivo da última troca de esquema terapêutico, momento da inclusão da Enfuvirtida no tratamento, todos os pacientes mencionaram a falha terapêutica:

Por conta de falência. Desde o começo ela sempretentou ver sezerava carga viral e nunca conseguia. (Entrevistado 8)

Porque foi falha terapêutica. Eu tive que entrar no resgate do resgate. Porque eu já tinha passado por todas as outras drogas. (Entrevistado 10)

Apesar das dificuldades supracitadas, estes pacientes também percebiam facilidades para conduzir os tratamentos anteriores, tais como os comprimidos não precisavam de um preparo anterior à administração, podiam ser administrados em qualquer lugar, o transporte destes era maisfácil eprático e, além disso, os horários eram mais cômodos. Estas facilidades podem ser percebidas nas seguintes falas: A facilidade era que a medicação era mais simples, eu tomava comprimido e pronto. Tava liberado pelo resto do dia. A preocupação só era tomar na hora certa, para tomar era mais prático, era melhor. (Entrevistado 5)

0 anterior era muito fácil eprático, porque eu tomava ele em casa, na rua, em qualquer lugar, eu podia tomar a medicação. (Entrevistado 12)

Portanto, através dos depoimentos dos sujeitos, percebeu-se que, na condução dos tratamentos anteriores à Enfuvirtida, foram sentidas dificuldades, que interferiram de alguma forma na adesão destes à terapêutica e que acabaram por levar-Ihes à situação defal ha terapêutica eànecessidade de entrar no esquema com a Enfuvirtida.

Entretanto, alguns depoentes relataram que, no esquema anterior, havia facilidades em relação à via de administração. Todavia, este fato não impediu que houvessefal ha terapêutica, sendo necessário iniciar a terapia de resgate.

Categoria 2 - Tratamento atual:

da cognição à habilidade

Esta categoria abordou a visão dos pacientes acerca do tratamento atual, que contempla a Enfuvirtida, isto é, como eles percebiam este tra- tamento, quais eram as facilidades e/ou dificuldades percebidas por eles durante a condução do mesmo e como estava sendo a adesão a este novo tratamento.

0 tratamento com a Enfuvirtida traz consigo uma série de exigências, tais como a necessidade de um preparo anterior à administração, destreza manual por parte dos pacientes para se autoadministrar ou, quando isso não é possível, surge uma dependência de terceiros para fazer esta administração. Além disso, são necessários orientação e desenvolvimento cognitivo por parte dos pacientes para realizar todo o processo e todos estes fatores acabam se tornando dificultadores da correta condução desta terapêutica.

Uma das dificuldades bastante citada pelos pacientes dizia respeito à administração da medicação: Agora é uma injeção, tem que preparar, tem que sentir a dor da picadinha. É complicado. (Entrevistado 11)

Porque devido o Fuzeon, as seringas, é muito incômodo tomar duas vezes ao dia. Aquela furadinha todo dia. (Entrevistado 16)

Percebeu-se por meio dos discursos que as principais dificuldades estavam relacionadas à via de administração: o medo da autoadministração, a quantidade das doses, a dor e a preparação da medicação.

Logo, devido a esta dificuldade de se autoadministrar, alguns pacientes dependiam de terceiros para fazer as aplicações. Isto acabava por acarretar outros problemas, como a exposição desta outra pessoa ao vírus e mesmo o medo desta desecontaminar: A minha sobrinha équem faz as aplicações. Aí a mãe dela nem queria que ela aplicasse, com medo que ela se contaminasse e estragasse a vida dela. (Entrevistada 18)

Identificou-se desta forma que este era mais um problema vivenciado pelo paciente, o medo da contaminação de terceiros, que muitas vezes eles podiam se sentir responsabilizados por algum acidente com o material perfurocortante. Acredita-sequeestedado mereça atenção da equipe interdisciplinar, pois o paciente necessita de um cuidador, papel este muitas vezes assumido por um familiar. Entretanto, existe a possibilidade deum acidente com sangue. A equipe de profissionais deve estar atenta eajudar o pacientena seleção do cuidador, nas orientações em relação à biossegurança e utilização de equipamentos de proteção individual.

Outro fator bastante referido pelos pacientes foi o fato da medicação necessitar deum preparo prévio e de um local adequado para a administração da mesma. Isto pode ser observado no 
seguinte discurso: Agora com o Fuzeon, tem a dificuldade de manusear a seringa, preparar e um lugar de higiene. $\mathrm{E}$ a questão da privacidade também, com o Fuzeon vocêprecisa deum lugar fechado, um lugar tranquilo e tudo. Não pode fazer em lugar público, jamais eu vou fazer em lugar público. (Entrevistado 17)

Verificou-se que o preparo da administração da medicação requeria alguns cuidados especiais: noções de higiene, assepsia, destreza manual, boa acuidade visual. Muitas dessas condições eram difíceis para al guns pacientes, que viviam em condições precárias de moradia, ou que tinham perdas visuais ou motoras por sequela de doenças oportunistas, dentre elas a neurotoxoplasmose. Desta forma, faz-se necessário que equipe de saúde avalie a condição cognitiva e motora do paciente à realização da Enfuvirtida.

Ainda com relação às dificuldades, alguns pacientes relataram que a medicação restringiu mais as saídas de casa, principalmente as viagens, devido à complexidade do transporte da mesma e o desejo de que outras pessoas não tomassem conhecimento da sua doença. Este fator foi explicitado através da seguinte fala: Algumas restrições, por exemplo, eu não posso mais passar fim de semana fora, só se for pessoa muito íntima, porque é muita exposição. Você sair carregando seringas, medicação que tem que ser conservada em geladeira também é uma coisa que traz um pouquinho de complicação. (Entrevistado 13)

Por ser uma medicação que devia ser administrada de dozeem doze horas, alguns pacientes referiram sentir dificuldade de encaixar os horários das aplicações na sua rotina. Esta dificuldadefoi confirmada pelo seguinte discurso: Alterou muito a minha rotina, horário de acordar, horário de trabalho e horário das atividades físicas e de lazer também, porque às vezes, à noite, eu ia pra um local assim, agora eu tenho que ir antes ou depois da aplicação. Eu tenho sempreque estar em casa na hora da aplicação. (Entrevistado 12)

Percebeu-se pelos relatos acima que muitas dificuldades foram expostas pel os entrevistados, mas a principal delas tratava-se das reações nos locais de aplicação do Fuzeon, principalmente os nódulos, referidos por dezesseis (88\%) dos entrevistados, responsáveis em alguns casos pela interrupção do tratamento: Eu tenho consciência deque não tá tendo eficácia, porque o medicamento tem que ser tomado duas vezes ao dia. Eu tomo uma semana, aí eu fico cheio de edema, vou aplicar na outra semana e não consigo aplicar. Eu tô tomando uma semana, tomo uma semana e outra não. (Entrevistado 2)
Eu ainda não meadaptei não. Tá sendo muito difícil pra mim, muito difícil exatamente por causa dessa dificuldade que tem, quando chega lá no primeiro ponto, às vezes acontece de ainda ter nódulo, aí tem queficar procurando um lugar próximo pra aplicar. Já interrompi por bastante tempo. Por mais de seis meses devido a essa intolerância. (Entrevistado 10)

Identificou-sepor meio dos depoimentosque existia uma grande dificuldade em relação aos efeitos adversos da medicação; os mais citados foram os edemas e nódulos provocados pela via de administração, levando o paciente a fazer uso da terapia de forma equivocada.

Por isso, defende-se que a utilização desta medicação seja acompanhada pelo profissional enfermeiro, avaliando as intercorrências objetivas e subjetivas do processo de autoadministração ou do cuidador.

A pesar destes dados, vale ressaltar quealguns pacientes também viram facilidades no atual tratamento com o Fuzeon. Alguns relataram que conseguiram encaixar os horários da administração da injeção facilmente na sua rotina, principalmente pelo fato de não trabalharem: Facilidade eu tenho. Dá pra encaixar os horários, porque eu só vivo em função do HIV, eu não trabalho, eu não tenho nenhuma ocupação, então só vivo em relação a isso, dá pra conciliar uma coisa com a outra. (Entrevistado 6)

Outros referiram que o modo de preparar a medicação era fácil: A facilidade com o T20, a única facilidade que eu acho dele, é só o modo de preparar. (Entrevistado 10)

Sem dúvida, mesmo. Eu acho melhor tomar as injeções do que os comprimidos, apesar do medo todinho, sem dúvida é melhor. É fácil de preparar. (Entrevistada 18)

Com relação ao modo de preparar, ressalta-se a importância do trabalho feito pelas enfermeiras do ambulatório que atendiam a estes pacientes, visto que a maioria deles atribuía a facilidade com o preparo às orientações e ao suporte oferecido por estas profissionais, o que ficou bastante evidenciado pela fala: A priori, eu fique preocupado porqueeu não sabia queia ser subcutâneo eeu nunca tinha usado nenhuma aplicação. Então assim, a minha preocupação era assim, ter lidar com isso em mim. Então, será queeu tenho essa capacitação? Será que eu vou fazer essa coisa de forma correta? M as eu tive aqui e fui muito bem assistido pelo pessoal da enfermagem, mostrou um bicho de sete cabeças se tornar um bicho menor. (Entrevistado 15)

Com isso, percebeu-se que oferecer acolhimento e prestar um bom cuidado pode ajudar 
os pacientes a vencer alguns obstáculose, no caso da terapêutica medicamentosa, pode facilitar a adesão ao tratamento. Este dado pôde ser ratificado por $\mathrm{N}$ emes et al. ${ }^{8}$, que mostram que os trabalhos sobre tratamento com antirretrovirais têm confirmado a relação positiva entre aderência e boa qualidade do cuidado, destacando-se a relação com os profissionais de saúde.

Outra vantagem destetratamento sentida por alguns pacientes estava relacionada ao fato de ser uma medicação administrada por via parenteral, o que acabava por reduzir a quantidade de medicamentos orais e, consequentemente, as agressões provocadas por estes sobre o sistema gastrointestinal: A vantagem de ser uma aplicação, de ser uma injeção, éque também vocêpoupa seu estômago de tantas drogas, que imagino que todas elas sejam metabolizadas no fígado, mas de todo modo, você tem menos comprimido para ingerir. Isso é uma vantagem. (Entrevistado 15)

Mas o principal fator positivo da medicação referido pelos entrevistados, que vinha a estimular e a facilitar a adesão ao tratamento, foi o re sultado clínico quea medicação propiciava, identificado por estes tanto na melhora de seu estado geral, quanto nos resultados dos exames de carga viral eCD 4: Eu acho que eleébom pela questão que realmente funciona, porque em alguns dias eu já percebi uma melhora no meu quadro geral. Eu parei de perder peso, voltou a minha disposição, melhorou um pouco o meu humor. M elhorou tudo assim, fisicamente. (Entrevistado 12)

Eu não quero trocar essa medicação de jeito nenhum. 0 meu médico até perguntou: "olha se você quiser, você pode trocar". M as eu não quero, pra mim tá bom demais, minha carga viral tá indetectável, o meu CD 4 tá subindo e eu tô me dando com ela. Então pra mim tá muito bom. (Entrevistado 17)

Estefator positivo citado pel os sujeitos como facilitador da adesão e do sucesso da terapêutica está de acordo com Paiva et al. ${ }^{12}$; a partir do início do tratamento, todos concordam que, para a manutenção da aderência, o paciente deve conseguir acompanhar sua evolução: a eficácia pode ser percebida não apenas pela melhora visível em seu organismo, mas através de exames como CD 4 e carga viral.

Logo, percebeu-se que o tratamento com a Enfuvirtida também era visto pelos seus usuários como constituído por pontos positivos e negativos. Resta agora aos profissionais que acompanham estes pacientes valorizar esses pontos positivos identificados e procurar ajudá-los a enfrentar estas dificuldades na tentativa de obter uma melhor adesão, com vistas a obter resultados melhores do que os alcançados com os esquemas anteriores.

\section{Conclusão}

Constatou-se por meio do estudo realizado com pacientes em uso deEnfuvirtidaquea maioria era do sexo masculino ( $83 \%)$, solteiro (78\%), na faixa etária de 30 a 52 anos, com escolaridade variando do ensino fundamental incompleto ao ensino superior completo. Destes, $65 \%$ não trabalhavam. 0 grupo apresentou uma média de oito anos de tratamento com antirretrovirais e, quanto ao número de mudanças de esquemas, a maioria $(88,8 \%)$ trocou de uma a seis vezes.

Quanto aos depoimentos do grupo entrevistado, pode-se referir que fazer uso da terapia de resgate é ter vivido dificuldades com o esquema anterior em relação ao tamanho e à quantidade de medicamentos, é não ter tido diálogo com 0 médico e ter interrompido o tratamento. É também ter tido facilidades como o fácil manejo da medicação. É também ter dificuldades no tratamento atual como via de administração, horários, preparo, efeitos adversos, principalmente os nódulos no abdome. É ter medo que o cuidador se contamine na administração da medicação. E ter facilidades em relação a não ter efeitos gastrointestinais e apresentar melhora da carga viral.

Diante dos resultados obtidos, reforça-se a importância de um trabalho interdisciplinar, de forma que, ao serem identificados problemas de adesão ao tratamento, estes pacientes possam ser encaminhados para outros profissionais, como os enfermeiros e psicólogos, com vistas a ajudálos a melhor conduzirem a terapêutica ea vencerem estes obstáculos, evitando, assim, interrupções no tratamento e, possivelmente, uma falha terapêutica. Deste modo, pode-se pensar na importância do profissional de saúde no acompanhamento sistemático a estes pacientes de forma a trabalhar com uma escuta comprometida e um diálogo problematizador, numa perspectiva educativa. Acredita-se que a consulta de enfermagem éum momento em quea avaliação econdução do paciente pode ser realizada numa perspectiva clínica e educativa, educação entendida como um lugar à reflexão e de liberdade.

Trabal hos em grupo seria outro artifício que poderia ser utilizado com estes pacientes, como grupos de adesão, nos quais estes pudessem trocar experiências e encontrar meios de enfrentamento para as suas dificuldades elimitações, vis- 
to que, pelos depoimentos dos entrevistados, as referências acerca do novo tratamento ea reação positiva de outros pacientes servem como incentivo para iniciar e também para dar continuidade ao tratamento.

\section{Colaboradores}

DVM Torres participou de todas as etapas da elaboração do artigo; KCL Miranda trabalhou na concepção teórica e redação final do texto.

\section{Referências}

1. Brasil. M inistério da Saúde. Boletim Epidemiológico - Ano III, no 1. [site da Internet] [acessado 2007 abr 05]. Disponível em: http://www.aids.gov.br/data/ documents/storedD ocuments/\%7BB8EF5DAF -23AE4891-AD36-1903553A3174\%7D/\%7B6B12D 137-92DF4CF5-A35A-482AED 64CBC 0\% 7D/BO LETIM 2006 internet.pdf

2. Souza MVN, Almeida MV. Drogas Anti-HIV: passado, presente e perspectivas futuras. Quim. Nova 2003; 26(3):366-372.

3. Carvalho CV, Duarte DB, Merchan-Hamann E, Bicudo $E$, Laguardia J. Determinantes da aderência à terapia antir-etroviral combinada em Brasília, Distrito Federal, Brasil, 1999-2000. Cad Saude Publica 2003; 19(2):593-604.

4. Rachid M, Schechter M. M anual de HIV/aids. 8a ed. Rio de Janeiro: Revinter; 2004.

5. Bardin L. Análise de conteúdo. Lisboa: Edições 70; 1979.

6. Lalezari JP, Eron JJ, Carlson M, Cohen C, Dejesus E, Arduino RC, Gallant JE, Volberding P, Murphy RL, Valentine F, Nelson EL, Sista PR, Dusek A, Kilby JM. A phase II clinical study of the long-term safety and antiviral activity of enfuvirtide-based antiretroviral therapy. AIDS 2003; 17(5):691-698.

7. Leite SN, Vasconcelos M PC. Adesão à terapêutica medicamentosa: elementos para a discussão de conceitos e pressupostos adotados na literatura. Cien Saude Colet 2003; 8(3):111-122.

8. Nemes M IB, Jordan MS, Okazaki E, Lopes JF, Komatsu CL. Aderência ao tratamento antirretroviral em aids: revisão da literatura médica. In: Teixeira PR, Paiva V, Shimma E, organizadores. Tá difícil de engolir? Experiências de adesão ao tratamento antiretroviral em São Paulo. São Paulo: Nepaids; 2000. 
9. Tunala L, Paiva V, Ventura-Filipe E, Santos TLL, Santos N, Hearst N. Fatores psicossociais que dificultam a adesão das mulheres portadoras do HIV aos cuidados de saúde. In: Teixeira PR, Paiva V, Shimma $E$, organizadores. Tá difícil de engolir? Experiências de adesão ao tratamento antirretroviral em São Paulo. São Paulo: Nepaids; 2000.

10. Freire P. Pedagogia da esperança: um reencontro com a pedagogia do oprimido. 7a ed. Rio de Janeiro: Paz e Terra; 2000.

11. Acurcio FA, Guimarães MDC. Utilização de medicamentos por indivíduos HIV positivos. Rev. Saude Publica 1999; 33(1): 73-84.

12. Paiva V, Leite $B, N$ igro $R$, Caraciolo J. Lidando com a adesão - A experiência de profissionais e ativistas na cidade de São Paulo. In: Teixeira PR, Paiva V, Shimma E, organizadores. Tá difícil de engolir? Experiências de adesão ao tratamento antirre troviral em São Paulo. São Paulo: Nepaids; 2000.

Artigo apresentado em 02/09/2007

Aprovado em 14/12/2007 